\title{
Clustering of multiple lifestyle behaviours and its relationship with weight status and cardiorespiratory fitness in a sample of Flemish 11- to 12-year-olds
}

\author{
Jan Seghers* and Cindy Rutten \\ Department of Human Kinesiology, Katholieke Universiteit Leuven, Tervuursevest 101, 3001 Leuven, Belgium
}

Submitted 30 April 2009: Accepted 20 January 2010: First published online 18 March 2010

\begin{abstract}
Objective: The aim of the present study was to explore the existence of clusters in multiple lifestyle behaviours, including physical activity (PA), sedentariness and food habits, in young adolescents. The present study also investigated whether the identified groups could be characterised by gender and components of health-related physical fitness, especially weight status and cardiorespiratory fitness (CRF).

Design: A cross-sectional survey. Leisure-time PA, sedentary behaviour and food consumption were assessed by a questionnaire. Overweight prevalence was estimated using BMI $\left(\mathrm{kg} / \mathrm{m}^{2}\right)$ calculated from self-reported height and weight. CRF was measured using a $20 \mathrm{~m}$ shuttle-run test.

Setting: The study was conducted in four middle schools in Flanders, Belgium. Subjects: The sample size was 317 seventh grade students aged 11-12 years.

Results: Four reliable and meaningful lifestyle clusters could be identified, labelled as 'Sporty media-oriented mixed eaters' (boys: $n$ 34; girls: $n$ 16), 'Academic healthy eaters' (boys: $n$ 30; girls: $n$ 58), 'Inactive healthy eaters' (boys: $n$ 38; girls: $n 57)$ and 'Inactive media-oriented unhealthy eaters' (boys: $n$ 35; girls: $n$ 49). The lifestyle clusters could not be characterised by adolescents' weight status. Among boys, the 'Sporty media-oriented mixed eaters' group performed significantly better on the shuttle-run test than those in clusters with the lowest levels of PA (clusters 3 and 4).

Conclusions: Our results showed that healthy and risk-related behaviours may coexist in some groups of young adolescents. Isolated unhealthy behaviours, such as high levels of screen-based media use or high consumption of energydense food items, are not necessarily related with negative health outcomes, on the condition that these risk-related behaviours co-occur with more healthenhancing behaviours such as PA.
\end{abstract}

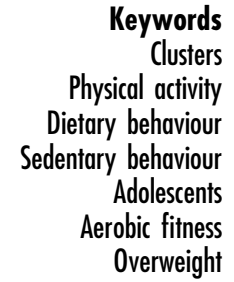

Clusters

Physical activity

Dietary behaviour

Adolescents

Overweight
Dramatic increases in childhood obesity over the past decades suggest the predominance of influential behavioural factors over genetic factors. It is generally believed that today's environment enforces an inactive lifestyle that is likely to contribute to a positive energy balance and childhood obesity ${ }^{(1)}$. Despite the important role of nutrition (energy input) and physical activity (PA; energy output) in the prevention of childhood obesity, there seems to be limited research addressing the relationship between multiple health behaviours or clusters based on this energy-balance approach ${ }^{(2-4)}$. Previous literature in this area has mainly focused on describing bivariate associations between PA and sedentary behaviour ${ }^{(5)}$, PA and food choices ${ }^{(6,7)}$ or sedentary behaviour and food choices $^{(8,9)}$. Although significant relationships may exist between two health behaviours, the reported correlations are predominantly weak and often too small to be of much clinical or practical significance. Nevertheless, the low correlations between health-related behaviours does not exclude the existence of clusters or groups of young people who show negative health profiles due to factors such as low PA levels, high televison (TV) watching and unhealthy food choices ${ }^{(10)}$. In addition, previous research has shown that we cannot assume that all children who eat healthily are also sufficiently physically active and vice versa $^{(11)}$. Consequently, a better understanding of clustering of multiple health behaviours in young people is needed to inform effective interventions ${ }^{(4,12)}$.

Cluster analysis is frequently used in health research to identify mutually exclusive, homogeneous groups of individuals sharing numerous characteristics. The rationale behind studying the clustering of health behaviours 
lies in the fact that it can identify high-risk groups and thus provide a first step towards effective primary prevention strategies ${ }^{(13)}$. Previous studies examining the clustering of multiple health-related behaviours mainly focused on patterns in sedentary and exercise behaviours $^{(14-19)}$. From an energy regulation perspective, however, it is clear that we need to focus on both energy input and energy output ${ }^{(2)}$. Only a few prior studies have addressed the clustering of PA and food habits in youth $^{(11,20)}$, but they failed to incorporate sedentary behaviours. Therefore, the first aim of the present study was to explore the existence of clusters in multiple lifestyle behaviours, including PA, sedentary pursuits and food choices, in a sample of seventh graders aged 11-12 years. In addition, we investigated whether the identified clusters could be characterised by gender, weight status and cardiorespiratory fitness (CRF). CRF is a key component of overall physical fitness and higher levels of CRF are associated with a healthier cardiovascular profile in children and adolescents ${ }^{(21)}$

\section{Experimental methods}

\section{Sampling procedure}

All middle schools in the region of Leuven, a mediumsized city of Flanders (Belgium), were eligible for participation in the study. Six schools were randomly selected out of the forty-three eligible schools. Two of the six school principals approached by telephone declined participation because of lack of time. In each of the four participating schools, all of the seventh graders were invited to participate. An informed consent was obtained from the school board and all parents. Owing to illness, ten $(3 \cdot 1 \%)$ of the 327 students were absent on the day of data collection. Unfortunately, no further information on these non-participants regarding their health-related behaviours was available. The final sample consisted of 317 students ( 137 boys and 180 girls) with a mean age of 11.7 (SD 0.5) years. Data were collected in October and November 2007 during a physical education lesson at school lasting $50 \mathrm{~min}$. The study protocol was approved by the ethical committee of the Katholieke Universiteit Leuven.

\section{Measures}

\section{Leisure-time physical activity}

Despite many PA opportunities during school hours (e.g. school recess), numerous studies have shown that a substantial proportion of young people's daily PA occurs outside the school hours ${ }^{(22,23)}$. In the present study, the pupils' PA behaviour during leisure time was assessed making use of the Flemish Physical Activity Questionnaire, whose reliability and validity has been described elsewhere ${ }^{(24)}$. Leisure-time physical activity (LTPA) was assessed by asking for children's main sports practised in leisure time (compulsory school physical education, school sports and active transportation did not count for PA in leisure time). For each activity, they reported the frequency and the usual time they spend on that activity. For describing our sample, the level of LTPA was dichotomised and a low-activity profile was defined as $0-3 \mathrm{~h} /$ week involvement in LTPA, which is consistent with previous research $^{(19)}$. This is different from the internationally wellaccepted recommendation that children should engage in moderate-to-vigorous PA for at least $1 \mathrm{~h} / \mathrm{d}^{(25)}$, because in the present study we were not able to assess engagement in physical activities during school hours or active transportation. For the cluster analyses, the total time spent in LTPA (expressed as h/week) was used.

\section{Sedentary behaviour}

There are specific domains of sedentary behaviour that have both content and face validity. During after school hours, screen-based sedentary behaviours (TV, videos and computers) and school homework have been identified as the most prevalent sedentary activities ${ }^{(26)}$. Therefore, this part of the questionnaire was developed to measure a range of sedentary activities common among adolescents reported in the literature ${ }^{(26)}$. With respect to the screen-based sedentary behaviours, the participants were asked to report the time $(\mathrm{h} / \mathrm{d})$ they usually spent in TV viewing, computer use (excluding computer-based homework) and playing electronic computer games on a typical school day and at the weekend. For describing our sample, high TV viewing was defined as $>2 \mathrm{~h} / \mathrm{d}$ and for computer use (including electronic computer games) the cut-off was set at $>1 \mathrm{~h} / \mathrm{d}$, which is consistent with cut-offs used in other study ${ }^{(8,18)}$. For the cluster analyses, a composite measure of screenbased media use (expressed as h/week) was calculated by summing the time spent watching TV, using the computer and playing computer games. In addition, children were asked to report the weekly time (h/week) they spent doing study or homework, as an index of time spent on educational activities.

\section{Dietary behaviour}

A Dutch version of a validated $\mathrm{FFQ}^{(27)}$ was used to assess children's eating practices. In the present study, five healthy food items (wholemeal bread, fruits, vegetables, fish and milk/diary products) and five risk-related (energy-dense) food items (white bread, meat, soft drinks, fast food and sweets/chips) were chosen to characterise dietary pattern. Food items were classified in categories as follows: $1=$ never, $2=1-2$ times/week, 3=3-5 times/week and $4=$ daily. Although overestimation of the mean consumption frequency of food items must be considered using the FFQ, a satisfactory test-retest reliability of the FFQ items (intra-class correlation coefficient $=0 \cdot 68$ ) has been demonstrated elsewhere ${ }^{(28)}$. On the basis of children's responses, two dietary indices were calculated. A 'healthy food index' 
and a 'risk-related food index' were calculated by summing the frequency of the consumption of the five 'healthy' and the five 'risk-related' food items, respectively. Children indicating 'never' to eat these food products scored 5, while score 20 was allocated to children consuming all considered food items 'daily'.

\section{Overweight}

Self-reported weight and height were used to calculate the BMI $\left(\mathrm{kg} / \mathrm{m}^{2}\right)$. The International Obesity Task Force criteria were used to define overweight and obesity ${ }^{(29)}$. These criteria identify gender- and age-adjusted BMI values associated with a predicted BMI of $25 \mathrm{~kg} / \mathrm{m}^{2}$ (overweight) and $30 \mathrm{~kg} / \mathrm{m}^{2}$ (obesity) at the age of 18 years.

\section{Cardiorespiratory fitness}

CRF was assessed indirectly using the $20 \mathrm{~m}$ progressive shuttle-run test with 1 min stages and expressed as the running speed in $\mathrm{km} / \mathrm{h}$ at the final completed stage ${ }^{(30)}$. All measurements were carried out under standardised conditions. All students were familiar with the test because this is a commonly used fitness tests in the physical education curriculum in Belgium.

\section{Statistical analyses}

Data management and computations of descriptive statistics and prevalence rates were performed using the Statistical Package for the Social Sciences statistical software package version $15 \cdot 0$ for Windows (SPSS Inc., Chicago, IL, USA) and the significance level was set at $P<0 \cdot 05$. Means, standard deviations and/or proportions were calculated for the key variables. Spearman rank correlations were calculated as a measure of association between the different behaviours. Gender differences in proportions of the behaviours were tested with $\chi^{2}$ tests.

Consistent with previous research ${ }^{(11,19)}, \boldsymbol{\kappa}$-means cluster analysis was used to identify specific patterns in five health behaviour indices. $\boldsymbol{\kappa}$-means clustering places children in mutually exclusive groups characterised by their PA behaviour, sedentary pursuits and food habits. Before clustering, all variables were transformed into standardised $Z$-scores. This prevents variables measured in larger ranges from contributing to the distance to a larger extent than variables with smaller ranges do. A possible instability of the cluster solution could be one of the cluster analysis' drawbacks. Therefore, the reliability of the created cluster solution was examined on a random sample of $50 \%$ of the total sample. In addition, a kappa degree of agreement in cluster membership was calculated by comparing memberships of the subsample with these of the total sample. Following these procedures, we specified three-, four- and five-cluster solutions. The fourcluster solution was found to be the most reliable and meaningful regarding the different patterns found and is reported in the Results section. The different clusters are given labels that characterise the behavioural pattern.
These labels may reflect a value judgement, which was not intended as such, but was used as an efficient way to further describe our results regarding the clusters.

Cluster differences on gender distribution and pupils' weight status were examined with $\chi^{2}$ tests. By means of the ANOVA and a Bonferroni post hoc test, cluster differences on the selected behavioural indices and CRF levels were investigated. Partial $\eta^{2}$ were calculated as a measure of effect size. For overweight and CRF, these tests were controlled for gender.

\section{Results}

\section{Pupil's characteristics}

Sample characteristics are presented in Table 1. Gender differences in proportions of health-related behaviours were observed for LTPA, computer use and some risk-related food habits. In particular, a significantly higher proportion of boys was found for high LTPA and high computer use compared to girls. Some gender differences were also observed regarding type of sports, with boys being more involved in endurance sports and soccer but less involved in dance. With respect to their food habits, boys reported more daily consumption of meat and soft drinks than girls. Approximately $9.5 \%$ of our sample was categorised as overweight (including obesity), but no gender difference in overweight prevalence was observed. With respect to educational activities, girls spent significantly more time on school homework than boys (girls: $14 \cdot 7$ (SD 6.9) h/week; boys: $11 \cdot 3($ sD $7 \cdot 3) \mathrm{h} /$ week; $P<0 \cdot 01$ ).

\section{Description of the clusters}

Spearman's correlation coefficients between the five health behaviour indices were very low to moderate ( $r$-values ranged from -0.433 to $0 \cdot 319$; see Table 2 ). On the basis of five health behaviour indices, the applied $\kappa$-means cluster analysis resulted in four reliable and meaningful lifestyle clusters. The stability of this cluster solution was guaranteed by repeating the procedure in a randomly selected subsample of the total sample and good agreement was found (Cohen's $\kappa=0 \cdot 79, P<0 \cdot 001$ ). Distinguishing characteristics of each cluster are identified by high or low Z-scores. As shown in Fig. 1, cluster 1 ('Sporty media-oriented mixed eaters', $n$ 50) shows high $Z$-scores (above 0) on all behaviours, except for time spent on educational activities $(Z$-score $=-0 \cdot 60$ ). Cluster 2 ('Academic healthy eaters', $n$ 88) shows an average level of LTPA $(Z$-score $=0 \cdot 10)$, but has high values on homework and healthy food index combined with low Z-scores (below 0) for screen-based media use and consumption of risk-related food items. Cluster 3 ('Inactive healthy eaters', $n$ 95) has low $Z$-scores on all behaviours, except for the consumption of healthy food items $(Z$-score $=0 \cdot 50$ ). Cluster 4 ('Inactive media-oriented unhealthy eaters', $n$ 84) is characterised by high $Z$-scores on screen-based media use and risk-related 
Table 1 Gender-specific prevalence rates (\%) of the self-reported health-related behaviours, sports type preference and weight status in 317 Flemish adolescents

\begin{tabular}{|c|c|c|c|c|}
\hline & Total $(n 317)$ & Boys ( $n$ 137) & Girls (n 180) & $\chi^{2}$ value \\
\hline \multicolumn{5}{|l|}{ Leisure-time physical activity } \\
\hline Low activity profile (0-3h/week) & $59 \cdot 5$ & $45 \cdot 3$ & $70 \cdot 4$ & \multirow[t]{2}{*}{$20 \cdot 35^{\star}$} \\
\hline High activity profile ( $>3 \mathrm{~h} /$ week) & $40 \cdot 5$ & $54 \cdot 7$ & $29 \cdot 6$ & \\
\hline \multicolumn{5}{|l|}{ Sports practised } \\
\hline Dance & $22 \cdot 6$ & $2 \cdot 9$ & $37 \cdot 8$ & $54 \cdot 26^{*}$ \\
\hline Running/athletics & $21 \cdot 7$ & $30 \cdot 4$ & $15 \cdot 0$ & $10 \cdot 95^{*}$ \\
\hline Bicycle touring & $19 \cdot 2$ & $24 \cdot 6$ & $15 \cdot 0$ & $4 \cdot 68^{\star \star}$ \\
\hline Soccer & $19 \cdot 2$ & $41 \cdot 3$ & $2 \cdot 2$ & $76 \cdot 96^{*}$ \\
\hline Tennis & $14 \cdot 5$ & $18 \cdot 1$ & $11 \cdot 7$ & $2 \cdot 63$ \\
\hline Swimming & $12 \cdot 9$ & $12 \cdot 3$ & $13 \cdot 3$ & 0.07 \\
\hline Volleyball & $4 \cdot 4$ & $3 \cdot 6$ & $5 \cdot 0$ & 0.35 \\
\hline Gymnastics & $4 \cdot 4$ & $3 \cdot 6$ & $5 \cdot 0$ & 0.35 \\
\hline \multicolumn{5}{|l|}{ Screen-based media use } \\
\hline High TV viewing $(>2 \mathrm{~h} / \mathrm{d})$ & $45 \cdot 2$ & $45 \cdot 5$ & $45 \cdot 0$ & 0.93 \\
\hline High computer use $(>1 \mathrm{~h} / \mathrm{d})$ & $39 \cdot 2$ & $47 \cdot 0$ & $33 \cdot 5$ & $5 \cdot 77^{\star \star}$ \\
\hline \multicolumn{5}{|l|}{ Healthy food items } \\
\hline Daily wholemeal bread intake & $33 \cdot 8$ & $33 \cdot 8$ & $33 \cdot 7$ & $1 \cdot 35$ \\
\hline Daily fruit intake & $50 \cdot 0$ & $47 \cdot 5$ & $52 \cdot 0$ & $3 \cdot 76$ \\
\hline Daily vegetable intake & $77 \cdot 1$ & $75 \cdot 7$ & $78 \cdot 2$ & $1 \cdot 75$ \\
\hline Daily milk/dairy products intake & $56 \cdot 2$ & $55 \cdot 9$ & $56 \cdot 4$ & $0 \cdot 79$ \\
\hline Daily fish consumption & $2 \cdot 6$ & $5 \cdot 2$ & $1 \cdot 1$ & $7 \cdot 60$ \\
\hline \multicolumn{5}{|l|}{ Risk-related food items } \\
\hline Daily white bread intake & $43 \cdot 5$ & $45 \cdot 5$ & $42 \cdot 0$ & $1 \cdot 38$ \\
\hline Daily meat intake & $42 \cdot 0$ & $47 \cdot 4$ & $37 \cdot 8$ & $8 \cdot 03^{\star *}$ \\
\hline Daily sweets intake & $14 \cdot 2$ & $17 \cdot 5$ & $20 \cdot 6$ & 0.57 \\
\hline Daily soft drink consumption & $27 \cdot 6$ & $33 \cdot 1$ & $23 \cdot 5$ & $9 \cdot 91^{* *}$ \\
\hline Daily fast food intake & $1 \cdot 6$ & $2 \cdot 2$ & $1 \cdot 1$ & $7 \cdot 60$ \\
\hline \multicolumn{5}{|l|}{ Weight status } \\
\hline Overweight & $8 \cdot 2$ & $9 \cdot 8$ & $6 \cdot 9$ & $0 \cdot 90$ \\
\hline Obese & $1 \cdot 3$ & $1 \cdot 5$ & $1 \cdot 2$ & \\
\hline
\end{tabular}

Frequencies were significantly different between boys and girls: ${ }^{\star} P<0 \cdot 01,{ }^{\star \star} P<0.05$.

Table 2 Inter-correlations of indices indicating health-related lifestyle behaviors in 317 Flemish adolescents

\begin{tabular}{lcccc}
\hline & $\begin{array}{c}\text { Homework } \\
\text { (h/week) }\end{array}$ & $\begin{array}{c}\text { Screen-based } \\
\text { media use (h/week) }\end{array}$ & $\begin{array}{r}\text { Healthy food index } \\
\text { (scale: 5-20) }\end{array}$ & $\begin{array}{r}\text { Risk-related food } \\
\text { index (scale: 5-20) }\end{array}$ \\
\hline Leisure-time physical activity (h/week) & -0.041 & $0 \cdot 049$ & $0 \cdot 174^{\star}$ & $-0 \cdot 054$ \\
Homework (h/week) & & $-0 \cdot 195^{\star}$ & $0 \cdot 101$ & $-0 \cdot 153^{\star}$ \\
Screen-based media use (h/week) & & & $-0 \cdot 218^{\star}$ & $0 \cdot 319^{\star}$ \\
Healthy food index (scale: 5-20) & & & $-0 \cdot 433^{\star}$ & ${ }^{*}$ \\
\hline
\end{tabular}

Spearman's $\rho$ correlation coefficients were significantly different from 0 : ${ }^{*} P<0.01$.

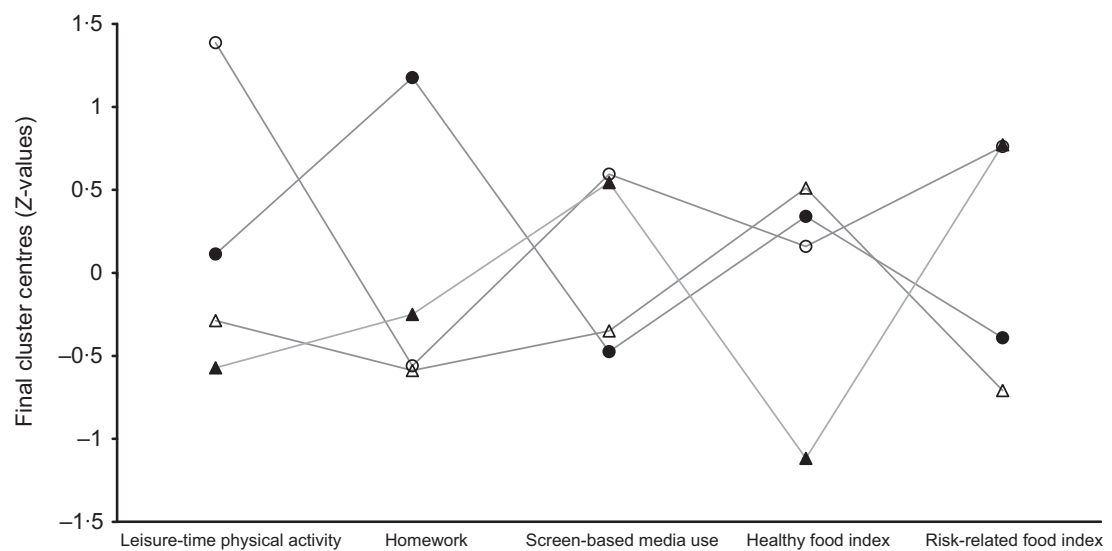

Fig. 1 Patterns of the final cluster centres (expressed as standardised Z-values) of the selected lifestyle behaviour factors, identified using $\kappa$-means cluster analysis; $-\_$, Sporty media-oriented mixed eaters; $\bullet-$, Academic healthy eaters; $\triangle$, Inactive healthy eaters; $\_$- Inactive media-oriented unhealthy eaters 
food consumption but low Z-scores on LTPA and healthy food index. Mean absolute values of the behavioural factors by cluster solution are presented in Table 3 .

\section{Association between lifestyle clusters and gender, weight status and cardiorespiratory fitness}

Table 4 presents the association between cluster solution and gender distribution, overweight prevalence (including obesity) and CRF. For overweight and CRF, the results were controlled for gender. With respect to gender distribution, boys formed the majority of the first cluster, whereas the girls formed the majority of the other clusters. After controlling for gender distribution, the different clusters could not be characterised by pupils' weight status, although the lowest prevalence rate for overweight (including obesity) was observed for the boys and girls in the 'Sporty media-oriented mixed eaters' group. With respect to CRF, a significant relationship between the shuttle-run test performance and lifestyle cluster membership was observed for boys only $(P<0 \cdot 05$; partial $\left.\eta^{2}=0 \cdot 10\right)$. Post hoc tests revealed that the final speed of boys belonging to the 'Sporty media-oriented mixed eaters' group was approximately $1 \mathrm{~km} / \mathrm{h}$ or two stages higher than their counterparts in clusters 3 and 4 .

\section{Discussion}

The first objective of the present study was to explore the existence of clusters in multiple health behaviours including LTPA, sedentary behaviour and food habits in a sample of Flemish pupils aged 11-12 years. Despite the lack of strong correlations between the single behavioural indices, the applied $\kappa$-means cluster analysis showed that co-occurrence of specific PA, sedentary and dietary components may exist within certain groups of adolescents. For instance, the 'Sporty media-oriented mixed eaters' (comprising $15 \cdot 8 \%$ of our sample) represent a lifestyle that could be called a sporting lifestyle, although sports participation was not their only interest. Even though their LTPA index was very high, adolescents in this group also reported high amounts of screen-based media use. Comparable lifestyle profiles were also reported in other studies and were labelled as 'techno-actives, ${ }^{,(14)}$, 'general activists' ${ }^{\text {(15) }}$ or

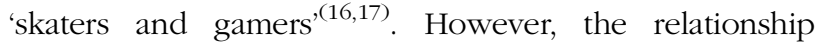
between PA and screen-based sedentary behaviour is the subject of debate ${ }^{(31)}$. Whereas some have suggested that those who engage less in PA are more likely to watch a lot of $\mathrm{TV}^{(32)}$, more recent studies have suggested a weak relationship between screen-based sedentary activities (i.e. TV viewing) and PA in youth ${ }^{(18,19,26,33)}$. This suggests that there is time for both sedentary and active behaviours through the day and provides further support for the need to study more than one sedentary behaviour ${ }^{(31)}$. Apart from the screen-based sedentary behaviours, our adolescents in the 'Academic healthy eaters' group (comprising $27 \cdot 8 \%$ of

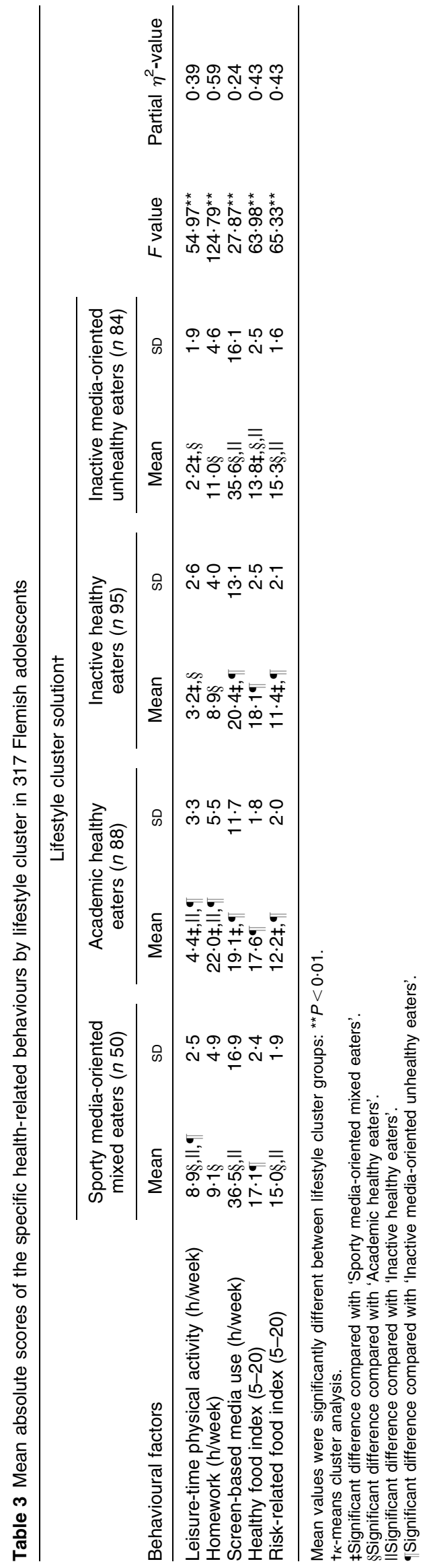


our sample) were highly occupied with educational activities but also demonstrated an above average level of LTPA behaviour ( $Z$-score above 0 ). This confirms previous research indicating that engagement in PA does not appear to displace the time spent for doing homework ${ }^{(26)}$.

From a public health perspective, the question appears to be whether or not a large volume of sedentary behaviour is compensated by a large enough volume of PA. It may therefore be more appropriate to speak of a sedentary behaviour compensation effect. Evidence for the compensation hypothesis has recently been found in a prospective cohort study among Flemish adolescents and showed that the relative risk of being overweight 2 years after the baseline measurement was considerably higher in those respondents who did not balance each $7 \mathrm{~h}$ of TV viewed per week by at least two and a half hours of PA per week ${ }^{(34)}$. Although high PA levels and high sedentaryrelated behaviours may coexist in some groups of adolescents at a particular stage in their life, longitudinal research has reported that PA declines throughout adolescence and is often replaced with less-active pursuits $^{(16)}$. Increasing PA and decreasing sedentary behaviours are therefore key factors in promoting health in youth ${ }^{(16)}$. On the basis of aforementioned considerations, the adolescents in our 'Inactive media-oriented unhealthy eaters' group (comprising $26.5 \%$ of our sample) may be at particular risk for developing chronic diseases later in life, not only because of their unbalanced screen timeLTPA ratio but also due to their low consumption of healthy food items in combination with a high consumption of energy-dense food items such as soft drinks and sweets/chips. Nonetheless, prospective cohort studies are needed to examine the stability of the identified cluster solution and to investigate the impact of this behavioural clustering on health outcomes later in life.

Our results pertaining to the second goal of the present study - the analysis of the association between lifestyle cluster membership and health-related physical fitness indices - revealed that the lifestyle clusters could not be characterised by the pupils' weight status. Some other research has found an association between lifestyle clusters and overweight in European 9- to 14-year-old boys, with the most unhealthy behaviour pattern having the highest risk of being overweight ${ }^{(19)}$. Nevertheless, the detected association was less evident in girls and their cluster analysis did not include food habits. Our finding is however consistent with another study reporting no significant association between lifestyle clusters including PA and food habits and overweight prevalence rates among 10-year-old Flemish children ${ }^{(11)}$. During adolescence, the pupil's body weight and body height is rapidly changing due to the adolescent growth spurt ${ }^{(35)}$. In fact, physiological demands of growth and maturation dictate that young people must necessarily be in a slight positive energy balance ${ }^{(2)}$. Consequently, this natural process of physical growth and developmental of (young) adolescents 
may have masked the relationship between lifestyle clusters and weight status in our sample. Nevertheless, it could be assumed that a continuous pattern of low PA, high media use and unhealthy eating might result in a higher overweight prevalence in cluster 4 ('Inactive media-oriented unhealthy eaters') in the long term. Longitudinal follow-up is needed to solve this question.

Our analysis regarding the association between cluster membership and CRF, on the other hand, revealed significant results, particularly among the boys. Boys in cluster 1 performed significantly better than boys in clusters 3 and 4 . These latter groups should therefore be encouraged to increase their PA levels. Although physical fitness is in part genetically determined, it can also be greatly influenced by environmental factors. PA seems to be a key element in physical fitness enhancement ${ }^{(36)}$. The present study clearly showed the well-known unequal PA pattern between boys and girls ${ }^{(37,38)}$ and gender differences in cluster allocation mainly reflected this higher LTPA engagement in boys. This may be one of the reasons for the lack of association between lifestyle cluster membership and CRF among girls. Moreover, boys as a group performed significantly better on the $20 \mathrm{~m}$ shuttle run test than the girls in present study (boys: $12 \cdot 0$ (SD 1.2) $\mathrm{km} / \mathrm{h}$; girls: $10.9(\mathrm{sD} 0.9) \mathrm{km} / \mathrm{h}, P<0 \cdot 01$ ). Our results also showed that boys practised different kinds of sports than girls (Table 1). On the basis of the compendium of energy expenditures for youth (expressed in metabolic equivalents or MET) ${ }^{(39)}$, it was found that our boys participated to a greater extent in sports involving higher levels of energy expenditure such as soccer (on average $8 \cdot 8 \mathrm{MET}$ ), bicycle touring (on average $6 \mathrm{MET}$ ) and running/athletics (on average $8.5 \mathrm{MET}$ ). This is an important finding, because previous research has observed that increased levels of vigorous PA ( $>6 \mathrm{MET}$ ), rather than light/moderate physical activity, are associated with higher CRF levels in children and adolescents ${ }^{(40)}$. In order to enhance physical fitness levels, intervention programmes might need to focus on physical activities with appropriate intensity ${ }^{(36)}$.

\section{Limitations}

The present study is subject to some limitations. First, the cross-sectional nature of the present study limits our ability to determine any causality in the results. Second, a relatively small sample was used. Although direct comparison between studies is hindered due to difference in year of data collection and/or recruited age groups, the frequencies of health-related behaviours and proportions of overweight in the current study were more or less in line with observations in other studies involving nationally representative samples ${ }^{(19,41)}$. Despite the speculated resemblance of the current sample to nationwide representative cohorts, generalisation of the results might not be appropriate.

A third limitation of the study was related to the fact that only a few factors were available for characterising the clusters and future studies should investigate other factors in order to better characterise these subgroups. Factors such as socio-economic status (SES) or environmental characteristics were not assessed but may also be relevant correlates of adolescents' lifestyles. Nonetheless, other research found no clear distinction between lifestyle clusters with respect to SES or environmental factors ${ }^{(11,18)}$. This lack of association may have been caused by the different impact of SES and environmental factors on single health behaviours in youth ${ }^{(42)}$. The association between lifestyle cluster allocation and SES or environmental factors may therefore disappear when multiple health behaviours are combined. Furthermore, it is important to keep in mind that school-related PA and active commuting to school were not assessed in the present study. Owing to the multifaceted character of PA, definitive statements regarding the association between our clusters and CRF cannot be made. With respect to active travel to school, for instance, previous research concluded that cycling to school was related to higher CRF levels in adolescents ${ }^{(43,44)}$. Cooper et al. ${ }^{(45)}$ also reported a positive association between active school travel and PA levels for adolescent girls. This may reflect the importance of PA accumulated while travelling to or from school and should therefore be taken into account in further research.

A final limitation of the present study is that prevalence data for overweight and obesity were derived from selfreported anthropometrics. Using self-reported height and weight instead of measured values is popular in many studies for practical or financial reasons. In the present study, all data (shuttle run test and completion of questionnaire) were collected during one physical education lesson that lasted $50 \mathrm{~min}$. Owing to this limited time frame, it was not feasible to measure all children's body dimensions. Nevertheless, using BMI values from selfreports may lead to an underestimation of the actual prevalence of overweight ${ }^{(46)}$ and should be taking into consideration while interpreting the results of the present study. However, correlation coefficients between selfreported and directly measured height and weight are generally high and self-reported anthropometrics are believed to be valuable if these are the only available source of data ${ }^{(47)}$. Previous research also showed that $96 \%$ of a large sample was correctly classified as obese on the basis of self-reported measures ${ }^{(48)}$.

\section{Conclusions}

A strength of the present study was the application of a cluster analysis, identifying patterns of behaviours relating to both energy input and energy output. From the cluster analysis, we can conclude that risk-related behaviours such as high levels of screen-based media use or high consumption of energy dense food items can be components of more than one lifestyle. For instance, in 
one lifestyle ('Sporty media-oriented mixed eaters') the association between screen-based media use and LTPA was positive, but was negative in another lifestyle cluster ('Inactive media-oriented unhealthy eaters'). Consequently, health-enhancing and risk-related behaviours may coexist in some groups of adolescents, which imply that healthrelated behaviours do not always discriminate in the same direction. Moreover, high levels of screen-based media use or high consumption of energy dense food items are not necessarily related with negative health outcomes, on the condition that these risk-related behaviours are compensated with healthy behaviours such as PA. This assumption can be supported by the significant higher CRF levels of the boys in the 'Sporty media-oriented mixed eaters' group, observed in the present study. Even though the practical implications are rather preliminary, the postulated compensation hypothesis may offer interesting pathways for prevention and intervention. However, this implies that children need selective advice on PA and eating habits in combination with clear reinforcements of healthy behaviours. As our clusters could not be identified by pupil's weight status, screening of health behaviour is needed. If young people could be assessed in terms of the cluster they belong to, effective ways of directing them to relevant advice could be developed.

\section{Acknowledgements}

The present study received no specific grant from any funding agency in the public, commercial or not-forprofit sectors. The authors have no conflict of interest to declare. J.S. developed and co-ordinated the overall study, carried out the statistical analysis and drafted the manuscript. C.R. supported in the statistical analysis and helped to draft the manuscript. The authors are grateful for all pupils, Physical Education teachers and school principals who collaborated in the study.

\section{References}

1. Brettschneider WD \& Naul R (2007) Obesity in Europe. Young people's physical activity and sedentary lifestyles. In Obesity in Europe. Young People's Physical Activity and Sedentary Lifestyles, pp. 7-26 [WD Brettschneider and R Naul, editors]. Frankfurt am Main: Peter Lang.

2. Dodd CJ (2007) Energy regulation in young people. J Sports Sci Med 6, 327-336.

3. Kumanyika SK, Obarzanek E, Stettler N et al. (2008) Population-based prevention of obesity - the need for comprehensive promotion of healthful eating, physical activity, and energy balance - a scientific statement from American Heart Association Council on Epidemiology and Prevention, Interdisciplinary Committee for Prevention (formerly the expert panel on population and prevention science). Circulation 118, 428-464.

4. Prochaska JJ, Spring B \& Nigg CR (2008) Multiple health behavior change research: an introduction and overview. Prev Med 46, 181-188.
5. Motl RW, McAuley E, Birnbaum AS et al. (2006) Naturally occurring changes in time spent watching television are inversely related to frequency of physical activity during early adolescence. J Adolesc 29, 19-32.

6. Sanchez A, Norman GJ, Sallis JF et al. (2007) Patterns and correlates of physical activity and nutrition behaviors in adolescents. Am J Prev Med 32, 124-130.

7. Kremers SPJ, De Bruijn GJ, Schaalma H et al. (2004) Clustering of energy balance-related behaviours and their intrapersonal determinants. Psychol Health 19, 595-606.

8. Boynton-Jarrett R, Thomas TN, Peterson KE et al. (2003) Impact of television viewing patterns on fruit and vegetable consumption among adolescents. Pediatrics 112, 1321-1326.

9. Vereecken CA, Todd J, Roberts C et al. (2006) Television viewing behaviour and associations with food habits in different countries. Public Health Nutr 9, 244-250.

10. Driskell MM, Dyment S, Mauriello L et al. (2008) Relationships among multiple behaviors for childhood and adolescent obesity prevention. Prev Med 46, 209-215.

11. Sabbe D, De Bourdeaudhuij I, Legiest E et al. (2008) A cluster-analytical approach towards physical activity and eating habits among 10-year-old children. Health Educ Res 23, 753-762.

12. Pronk NP, Anderson LH, Crain AL et al. (2004) Meeting recommendations for multiple healthy lifestyle factors prevalence, clustering, and predictors among adolescent, adult, and senior health plan members. Am J Prev Med 27, 25-33.

13. Schuit AJ, van Loon AJM, Tijhuis M et al. (2002) Clustering of lifestyle risk factors in a general adult population. Prev Med 35, 219-224.

14. Marshall SJ, Biddle SJH, Sallis JF et al. (2002) Clustering of sedentary behaviors and physical activity among youth: a cross-national study. Pediatr Exerc Sci 14, 401-417.

15. Telama R, Nupponen H \& Pieron M (2005) Physical activity among young people in the context of lifestyle. Eur Phys Educ Rev 11, 115-137.

16. Nelson MC, Gordon-Larsen P, Adair LS et al. (2005) Adolescent physical activity and sedentary behavior - patterning and longterm maintenance. Am J Prev Med 28, 259-266.

17. Nelson MC \& Gordon-Larsen P (2006) Physical activity and sedentary behavior patterns are associated with selected adolescent health risk behaviors. Pediatrics 117, 1281-1290.

18. Gorely T, Marshall SJ, Biddle SJH et al. (2007) Patterns of sedentary behaviour and physical activity among adolescents in the United Kingdom: Project STIL. J Behav Med 30, 521-531.

19. te Velde SJ, De Bourdeaudhuij I, Thorsdottir I et al. (2007) Patterns in sedentary and exercise behaviors and associations with overweight in 9-14-year-old boys and girls - a cross-sectional study. BMC Public Health 7, 16.

20. Kremers SPJ, De Bruijn GJ, Schaalma H et al. (2004) Clustering of energy balance-related behaviours and their intrapersonal determinants. Psychol Health 19, 595-606.

21. Anderssen SA, Cooper AR, Riddoch C et al. (2007) Low cardiorespiratory fitness is a strong predictor for clustering of cardiovascular disease risk factors in children independent of country, age and sex. Eur J Cardiovasc Prev Rehabil 14, 526-531.

22. Gidlow C, Cochrane T, Davey R et al. (2008) In-school and out-of-school physical activity in primary and secondary school children. J Sports Sci 26, 1411-1419.

23. Mota J, Santos P, Guerra S et al. (2003) Patterns of daily physical activity during school days in children and adolescents. Am J Hum Biol 15, 547-553.

24. Philippaerts RM, Matton L, Wijndaele K et al. (2006) Validity of a physical activity computer questionnaire in 12- to 18-year-old boys and girls. Int J Sports Med 27, $131-136$. 
25. Strong WB, Malina RM, Blimkie CJR et al. (2005) Evidence based physical activity for school-age youth. J Pediatr 146, 732-737.

26. Atkin AJ, Gorely T, Biddle SJH et al. (2008) Critical hours: physical activity and sedentary behavior of adolescents after school. Pediatr Exer Sci 20, 446-456.

27. Mast M, Körtzinger I \& Müller MJ (1998) Ernährungsverhalten und Ernährungszustand 5-7-jähriger Kinder in Kiel [Nutrition and nutritional state of 5-7 year old children in Kiel]. Aktuelle Ernährungsmedizin 23, 282-288.

28. Landsberg B, Plachta-Danielzik S, Much D et al. (2008) Associations between active commuting to school, fat mass and lifestyle factors in adolescents: the Kiel Obesity Prevention Study (KOPS). Eur J Clin Nutr 62, 739-747.

29. Cole TJ, Bellizzi MC, Flegal KM et al. (2000) Establishing a standard definition for child overweight and obesity worldwide: international survey. BMJ 320, 1240-1243.

30. Léger LA, Mercier D, Gadoury C et al. (1988) The multistage 20 metre shuttle run test for aerobic fitness. J Sports Sci 6, 93-101.

31. Biddle SJH (2007) Sedentary behaviour. Am J Prev Med 33, 502-504.

32. Eisenmann JC, Bartee RT \& Wang MQ (2002) Physical activity, TV viewing, and weight in US youth: 1999 Youth Risk Behavior Survey. Obes Res 10, 379-385.

33. Marshall SJ, Gorely T \& Biddle SJH (2006) A descriptive epidemiology of screen-based media use in youth: a review and critique. $J$ Adolesc 29, 333-349.

34. Van den Bulck J \& Hofman A (2009) The television-toexercise ratio is a predictor of overweight in adolescents: results from a prospective cohort study with a two year follow up. Prev Med 48, 368-371.

35. Rogol AD, Roemmich JN \& Clark PA (2002) Growth at puberty. J Adolesc Health 31, 192-200.

36. Ortega FB, Ruiz JR, Castillo MJ et al. (2008) Physical fitness in childhood and adolescence: a powerful marker of health. Int J Obes (Lond) 32, 1-11.

37. Sallis JF, Prochaska JJ \& Taylor WC (2000) A review of correlates of physical activity of children and adolescents. Med Sci Sports Exerc 32, 963-975.
38. Van der Horst K, Paw MJCA, Twisk JWR et al. (2007) A brief review on correlates of physical activity and sedentariness in youth. Med Sci Sports Exerc 39, 1241-1250.

39. Ridley K, Ainsworth BE \& Olds TS (2008) Development of a compendium of energy expenditures for youth. Int J Behav Nutr Phys Act 5, 45.

40. Ruiz JR, Rizzo NS, Hurtig-Wennlof A et al. (2006) Relations of total physical activity and intensity to fitness and fatness in children: the European Youth Heart Study. Am J Clin Nutr 84, 299-303.

41. Janssen I, Katzmarzyk PT, Boyce WF et al (2005) Comparison of overweight and obesity prevalence in school-aged youth from 34 countries and their relationships with physical activity and dietary patterns. Obes Rev 6, 123-132.

42. Van Lenthe FJ, Boreham CA, Twisk JWR et al. (2001) Socioeconomic position and coronary heart disease risk factors in youth: findings from the Young Hearts Project in Northern Ireland. Eur J Public Health 11, 43-50.

43. Cooper AR, Wedderkopp N, Jago R et al. (2008) Longitudinal associations of cycling to school with adolescent fitness. Prev Med 47, 324-328.

44. Andersen LB, Lawlor DA, Cooper AR et al. (2009) Physical fitness in relation to transport to school in adolescents: the Danish youth and sports study. Scand J Med Sci Sports 19, 406-411.

45. Cooper AR, Wedderkopp N, Wang H et al. (2006) Active travel to school and cardiovascular fitness in Danish children and adolescents. Med Sci Sports Exerc 38, 1724-1731.

46. Elgar FJ, Roberts C, Tudor-Smith C et al. (2005) Validity of self-reported height and weight and predictors of bias in adolescents. $J$ Adolesc Health 37, 371-375.

47. Sherry B, Jefferds ME \& Grummer-Strawn M (2007) Accuracy of adolescent self-report of height and weight in assessing overweight status. Arch Pediatr Adolesc Med 161, 1154-1161.

48. Tsigilis N (2006) Can secondary school students' selfreported measures of height and weight be trusted? An effect size approach. Eur J Public Health 16, 532-535. 